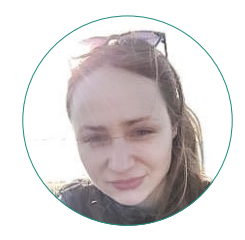

\author{
К. А. Попова
}

\title{
СТАНДАРТИЗАЦИЯ И ПРОФЕССИОНАЛИЗМ В РАБОТЕ ОПЕРАТОРОВ КОЛЛ-ЦЕНТРА
}

\section{Правильная ссылка на статью:}

Попова К.А. Стандартизация и профессионализм в работе операторов колл-центра // Мониторинг общественного мнения: экономические и социальные перемены. 2021. № 3. C. 105-133. https://doi.org/10.14515/monitoring.2021.3.1953.

\section{For citation:}

Popova K. A. (2021) Standardization and Professionalism in the Work of Call Center Operators. Monitoring of Public Opinion: Economic and Social Changes. No. 3. P. 105-133. https:// doi.org/10.14515/monitoring.2021.3.1953. (In Russ.) 
СТАНДАРТИЗАЦИЯ И ПРОФЕССИОНАЛИЗМ В РАБОТЕ ОПЕРАТОРОВ КОЛЛ-ЦЕНТРА

ПОПОВА Кристина Александровна MA, PhD студент, Королевский технологический институт КТН, Стокгольм, Швеция

E-MAIL: kpopova@kth.se

http://orcid.org/0000-0002-4320-4578

Аннотация. Статья посвящена работе колл-центра, обслуживающего справочную службу в одном из крупных городов России. Несмотря на обилие обращений к работе колл-центров в сфере критических исследований труда, их основной фокус традиционно направлен на менеджерские практики контроля и управления персоналом, тогда как "созидательная" часть - содержание работы и профессионализм операторов - часто остается за рамками анализа. В данной статье рассматривается один из ключевых аспектов работы операторов - производство ответов на вопросы. Используя конверс-анализ как основной методологический подход и анализируя транскрипты разговоров с операторами, мы показываем, что, хотя формально работа операторов сводится к зачитыванию текста из заранее подготовленной библиотеки ответов, она включает весомую аналитическую составляющую. Операторы играют роль переводчиков, ключевая задача которых состоит в установлении соответствия между абстрактной информацией нормативно-правовых актов и уникальными жизненными ситуациями граждан, звонящих в службу поддержки. Профессиональный оператор способен выполнять эту работу, маневрируя между нормами повседневной ком-
STANDARDIZATION AND PROFESSIONALISM IN THE WORK OF CALL CENTER OPERATORS

Kristina A. POPOVA 1 - MA, PhD Candidate E-MAIL: kpopova@kth.se http://orcid.org/0000-0002-4320-4578

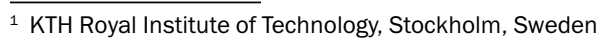

Abstract. The article focuses on the work of a call center operating as an inquiry service in a major Russian city. Despite there are multiple studies of call centers within the critical studies of work, their focus traditionally lies on the managerial practices of control, while the "productive" part of work - its content and the professionalism of operators - often remains unstudied. This article examines a key part of the call center work: answering the callers' questions. Utilizing the methodology of conversation analysis to analyze the transcripts of calls, we demonstrate that the operators' work includes much more than simply reading a ready-made text from the database of answers. The operator performs the function of an interpreter, whose key task consists in establishing correspondence between the abstract information of the database and the unique life situations of the callers seeking help in the inquiry service. A professional operator is able to perform this job while balancing between often contradictory norms of everyday communication and the internal rules of the call center. Even though professionals in many spheres approach rules with flexibility, the specific of call center work implies that the professionalism of operators exists under the threat of being punished for deviating from the workplace instructions; the professionalism 
муникации и внутренними правилами колл-центра, которые зачастую противоречат друг другу. Хотя гибкий подход к правилам характерен для профессионалов многих сфер, особенность труда в колл-центре состоит в том, что профессионализм операторов подразумевает риск наказания за отход от инструкций и не может быть институционализирован из-за требований стандартизации в колл-центре.

Ключевые слова: исследования рабочих мест, кол-центр, стандартизация, этнометодология, конверс-анализ

Благодарность. Я благодарна Артему Рейнюку, Борису Мельниченко, Илье Коновалову, Алисе Максимовой, Андрею Корбуту и Юлии Августис за комментарии и помощь в подготовке данного текста. Я также признательна всем участникам исследовательской группы EMCA_RU: Юлии Августис, Николаю Белову, Андрею Корбуту, Алисе Максимовой, Артему Рейнюку и Александру Широкову, чьи транскрипты я использовала в настоящей статье и с кем обсуждала представленные данные. of operators cannot be institutionalized because of the requirement of standardization in a call center.

Keywords: workplace studies, call center, standardization, ethnomethodology, conversation analysis

Acknowledgments. I am grateful to Artem Reynyuk, Boris Melnichenko, llya Konovalov, Alisa Maksimova, Andrei Korbut and Yulia Avgustis for comments and help in preparing this text. I am also grateful to all members of the EMCA_RU research group: Yulia Avgustis, Nikolai Belov, Andrei Korbut, Alisa Maksimova, Artem Reynyuk and Alexander Shirokov, whose transcripts I used in this article and with whom I discussed the reported data.

\section{Введение}

Зимой 2018 г. наша исследовательская группа побывала в колл-центре на короткой экскурсии и интервью с менеджерами. Нас преимущественно интересовал довольно неудачный "робот» - голосовой помощник, недавно внедренный в работу колл-центра. Робот пользовался ограниченным набором возможностей, и представить, что он в ближайшее время сможет заменить живых операторов, было сложно ${ }^{1}$.

Приведем пример диалога абонента с роботом:

«А: Меня зовут Иван Иванович, я проживаю в Подмосковье. Дело в том, что я обратился в больницу, где лежал с травмой глаза, и все время ходил к врачу без всяких проблем, она

1 Об особенностях коммуникации с роботом-оператором см. Корбут 2018, 2019; Максимова 2019, 2020. 
меня контролировала. А это пошел, а мне говорят, что теперь я должен платить шестьсот пятьдесят рублей, чтобы пройти к врачу. Раньше этого не было. У меня все.

P: Простите, я никак не могу понять. Пожалуйста, еще раз четко сформулируйте свой вопрос и говорите после звукового сигнала.

\#beep\#

А: В БОЛЬНИЦЕ ГОРОДА... города Серпухова... Городск... районная больница города Серпухова, чтобы обратиться... К ВРАЧУ БЕРУТ ПЛАТУ. ЭТО ПРАВИЛЬНО?» [Максимова, 2020: 106]

Ситуация предсказуемая, но парадоксальная, если вспомнить, что работа в коллцентре - образец “низкоквалифицированной" работы ${ }^{2}$, построенной вокруг идеала стандартизации. Сотрудники колл-центров обладают минимальной свободой выбирать, что и в какой момент они скажут, когда ответят на звонок и с кем будут разговаривать. Они обязаны соблюдать детальные рабочие инструкции и строго следовать сценариям разговоров с прописанной последовательностью реплик. Выполнение должностных инструкций обеспечивают строгие механизмы контроля: все разговоры записываются, все проблемные звонки и часть случайно отобранных записей прослушиваются менеджерами; длительность звонков и пауз отслеживается и анализируется, операторы, которые демонстрируют необычную статистику, контролируются отдельно, кроме того, помещение колл-центра - это "открытый офис", где занятость и вовлеченность сотрудников легко контролировать визуально. Отступления от сценариев чреваты штрафами, как и низкие оценки "производительности", жалобы пользователей или линейных супервайзеров.

Стандартизация и контроль - два столпа организации колл-центров, которые заставили исследователей говорить о колл-центре как об идеальном типе «электронного паноптикума» [Fernie, Metcalf, 1998], воплощении антиутопии тотального контроля, где полное знание о работе каждого сотрудника уничтожает любую возможность сопротивления и делает власть менеджмента тотальной.

Почему же в таком случае алгоритмы, которые по определению не способны отходить от правил и идеала стандартизации, оказываются не способны заменить живых операторов? Как мы покажем в основной части статьи, одна из причин несостоятельности алгоритмов состоит в том, что сама организация труда в колл-центре предполагает отход от внутренних правил. Колл-центры функционируют только потому, что операторы знают, как и когда нужно отклониться от должностной инструкции, чтобы соблюсти "нормальную" организацию разговора - Выстроить его таким образом, который будет приемлем для звонящих. С точки зрения умения маневрировать между правилами профессионализм операторов мало отличается от профессионализма в любой другой сфере экспертизы [Dreyfus, Dreyfus, 1980], но это отличие значительно. Оно заключается в том, что профессионализм операторов существует под постоянной угрозой наказания и не может быть институционализирован.

Мы будем рассматривать работу операторов, анализируя транскрипты звонков в информационно-справочный центр, расположенный в одном из крупных горо-

\footnotetext{
2 «Низкоквалифицированность" в данном случае относится к низким зарплатам, низкому входному порогу и низкому престижу, но ни в коей мере не подразумевает простоту или формальный статус данной профессии.
} 
дов России. Этот центр функционирует как публичная организация, где граждане могут получить разъяснения по оформлению документов, государственных услуг, контактов с государственными органами и схожих вопросов, касающихся взаимодействия с государственными структурами.

Задача операторов заключается в том, чтобы отвечать на вопросы звонящих. Формально ответы не требуют импровизации: операторы должны лишь зачитывать ответы из так называемой “базы знаний» - электронной библиотеки, где собрана информация по большинству возможных запросов. Однако, как мы продемонстрируем в основной части статьи, производство содержательных ответов требует сложно организованной работы. Часть ее состоит в том, чтобы "перевести" ответ с языка бюрократии, на котором он записан в базе, на язык, понятный звонящим. Перевод предполагает не только адаптацию языка, но и соотнесение абстрактной информации, которую операторы обязаны зачитать в соответствии с требованиями менеджмента, с конкретным запросом звонящих. Таким образом, работа операторов предполагает постоянное маневрирование между необходимостью соблюдать внутренние правила колл-центра и общепринятые правила коммуникации.

Методологически данная статья анализирует работу операторов колл-центра, исходя из этнометодологической традиции рабочих мест [Luff, Hindmarsh, Heath, 2000]. Используя транскрипты аудиозаписей разговоров с операторами как основной материал для анализа, мы сфокусируемся на организации разговора, но нас будут интересовать не структуры беседы самой по себе, а практики работы колл-центра и ключевой элемент такой работы-ответы на вопросы звонящих. Иначе говоря, мы будем анализировать прежде всего содержание работы операторов.

Безусловно, работа в колл-центре - это не только разговоры и ответы на запрос. Это точно также и системы мониторинга и контроля, штрафов и поощрений, физическое устройство рабочего пространства и технические возможности для мониторинга, которые делают колл-центры современным паноптикумом, а также те формы приспособления к и сопротивления контролю, которые практикуют сотрудники.

Наш тезис состоит в том, что конечный полезный продукт колл-центров является производной от навыков и мастерства операторов - представителей одной из самых "низкоквалифицированных", то есть непрестижных, низкооплачиваемых и не требующих профессионального образования профессий на рынке труда. Парадоксально, но колл-центр производит ответы на вопросы во многом вопреки формальным правилам, наличию "сценариев" разговора и постоянному контролю за соблюдением этих сценариев. Колл-центр работает только потому, что операторы умеют справляться с двумя противоречивыми наборами требований - отвечать на вопросы распознаваемых для звонящих образом и делать это так, чтобы формально соблюсти внутренние инструкции и не навлечь на себя санкции менеджеров.

\section{Две традиции исследования колл-центров и возможность для сближения}

Исследование колл-центров важно для двух традиций. Это критические исследования труда и исследования работы внутри этнометодологии и конверс-анализа, краткий обзор которых представлен ниже. 
Колл-центр в критических исследованиях

Критический подход к исследованию рабочих мест - преимущественно британская традиция индустриальной социологии, которая рассматривала работу через призму классового конфликта, как объект противостояния между менеджерами и рабочим классом [Braverman, 1974, Edwards, 1979, Friedman, 1977, Beynon, 1975]. Для критических исследований сферы труда колл-центр стал знаковым объектом. Колл-центры стали одним из ключевых объектов в дискуссии об изменениях в организации труда, которые произошли благодаря развитию новых технологий контроля. Спор шел о том, можно ли считать колл-центр образцом современного паноптикума, где из-за тотального технологического контроля рабочие полностью лишаются субъектности. Сторонники фуколдианской теории власти отвечали на этот вопрос положительно [Fernie, Metcalf, 1998], тогда как представители теории трудового процесса пытались показать, что контроль менеджеров не тотален, власть по-прежнему субъективна и наблюдаема, а конфликт между рабочими и менеджерами не исчез, несмотря на спад организованного сопротивления профсоюзов [Bain, Taylor, 2000; Callaghan, Thompson, 2001; Taylor, Bain, 1999, 2003].

Колл-центры содержат массу противоречий. Это яркий пример деквалификации экономики знания - появления внутри престижной “беловоротничковой» отрасли "низкоквалифицированной" и низкооплачиваемой профессии, схожей по своей организации с механизированным трудом заводских рабочих [Taylor, Bain, 1999]. Работа в колл-центре является одним из наиболее контролируемых и унифицированных типов труда, где каждое действие операторов измеряется, подсчитывается и регламентируется, но в то же время управляющие колл-центрами постоянно сталкиваются с тем, что качество услуг с трудом поддается подсчету и унификации, но важно для генерации прибыли [Bain et al., 2002; Callaghan, Thompson, 2002] Колл-центры - это трудовые площадки, где на первый план выходит «эмоциональный труд" [Hochschild, 1983], который не является гендерно или географически нейтральным: большинство сотрудников - женщины [Glucksmann, 2004], а коллцентры из Индии и Филиппин обслуживают население глобального англоговорящего севера [Wickham, Collins, 2004]. Весь этот набор антиномий сделал колл-центр популярным объектом для марксистских исследований труда в 1990-е и 2000-е годы. В последнее время интерес ученых несколько угас, что, вероятно, связано с выходом колл-центров на периферию технологического развития, но исследования продолжают появляться, давая более полное понимание организации труда и сопротивления в колл-центре с точки зрения рабочих [Woodcock, 2017] или показывая, как деквалификация распространяется на ранее привилегированную (в некоторых странах) сферу государственной службы [Pupo, Noack, 2009].

Исследования работы в колл-центрах позволяют составить представление об организации труда, устройстве систем контроля, рекрутинга и сопротивления. Интересно, что при всей "анти-менеджерской" позиции критических исследований эта традиция зачастую анализирует труд из перспективы, которая очень близка перспективе управленцев. Основное внимание направлено на менеджерские практики управления трудом, тогда как содержание и внутренняя структура работы, навыки и умения операторов оказываются на периферии научного интереса. 
Одно из немногих исследований, посвященных навыкам сотрудников коллцентра, указывает, что рекрутеры часто описывают навыки операторов как черты характера, говоря о дружелюбии, общительности, благожелательности. При такой операционализации навыки выглядят как природная склонность, а не результат профессионального развития - в отличие от технических навыков, характерных для более "квалифицированной" работы [Bolton, 2002; Callaghan, Thompson, 2002]. Существует риск, что даже критические исследования колл-центров, которые оставляют навыки сотрудников за пределами анализа, рассматривая работу операторов только в привязке к менеджерскому контролю и попыткам его избежать, поддерживают такую позицию, несмотря на очевидные симпатии к рабочим ${ }^{3}$.

Если придерживаться марксистского подхода, то подобный фокус критической традиции можно объяснить тем, что операторы существуют внутри капиталистической системы отчужденного труда, где содержание работы оказывается второстепенным по отношению к системам, обеспечивающим отчуждение. Мы предполагаем наличие “созидательной" части в работе операторов колл-центра и предлагаем сконцентрироваться на анализе того, как она оказывается возможной, несмотря на существующую систему организации труда.

\section{Конверс-аналитические и этнометодологические исследования колл-центров}

Для исследователей, работающих в традиции конверс-анализа, колл-центры были источником данных с начала 1960-х годов. Сразу несколько классических работ, включая диссертации Харви Сакса (1966) и Эмануэля Щеглова (1967), были написаны на основе материалов из государственных колл-центров в США. Сакс анализировал коммуникацию в центре психологической помощи и предотвращения самоубийств. Диссертация щеглова была основана на материалах звонков в полицию и неформальных телефонных переговоров между полицейскими [Mondada, 2008].

Учитывая интерес этнометодологов (ЭМ) и конверс-аналитиков (СА; совместно ЭМСА) к взаимодействию в естественной среде, неудивительно, что представители этих направлений начали анализировать разговоры в колл-центрах раньше, чем кто-либо еще [Kevoe-Feldman, 2019]. При этом изначально колл-центры представляли интерес в основном как источник аудиозаписей: если исследователей рабочего процесса интересовал классовый конфликт и его проявление на рабочем месте, конверс-аналитикам было важно проанализировать структуры разговора. Очевидно также различие между выбранными для анализа колл-центрами: ранние конверс-аналитики в основном интересовались профессиональными колл-центрами - диспетчерскими службами, где работают высококвалифицированные сотрудники, менее подверженные тотальному контролю и санкциям менеджмента.

\footnotetext{
${ }_{3}$ Содержание труда иногда попадало в фокус внимания исследователей рабочего процесса. Например, Бейн и Тейлор показывают, что объединение операторов в профсоюз произошло, потому что в компании была проблема с перенаправлением звонков на телефон горячей линии 999. Исследователи упоминают, что, чтобы решить эту проблему, операторы объединились и вступили в конфликт с менеджментом. Однако более подробно они этот или схожие случаи не рассматривают [Bain, Taylor, 2000].
} 
Организация труда и условия работы имели мало значения для первых ЭМСАисследований, однако были и те, кто приближался в своем интересе к критическим исследованиям труда. Так, одними из первых, кто начал анализировать звонки в государственные экстренные службы в соответствии с ЭМСА-традицией, стали Джек и Мэрилин Валены и Дон Циммерман [Whalen, 1995; Whalen, Whalen, Henderson, 2002; Whalen, Zimmerman, Whalen, 1988; Whalen, Zimmerman, 1987]. Исследования Дж. Валена основаны на этнографических наблюдениях и собственном опыте работы в диспетчерском центре, анализе видео-данных и подробном разборе транскриптов звонков. Одна из повторяющихся тем - анализ того, как, несмотря на уникальность каждого отдельного звонка, производится локальный порядок в колл-центрах [Whalen, 1995]. Циммерман также прибегает к детальному анализу транскриптов, показывая специфику переговоров с экстренной службой 911 в США. Он рассматривает отношения между уникальностью конкретных диалогов и типичностью переговоров с экстренной службой как устоявшейся социальной практики. Выделяя структуры организации разговора с диспетчерами, Циммерман показывает ситуативную работу операторов, которая требуется, чтобы перевести уникальные переживания и опыт звонящего в "рутинный" звонок, информация о котором может быть зафиксирована с помощью унифицированного бланка диспетчерской службы [Zimmerman, 1992b].

Хотя изначальный интерес к производству локального порядка не подразумевает критики колл-центров, и Циммерман, и Вален приходят к довольно критичным выводам. В частности, о том, что разделение работы на "рутинную" и "когнитивную" не оправданно, поскольку то, что выглядит как "рутинная" операция, на самом деле требует огромного объема сложно организованной работы, импровизации и мастерства, которые просто остаются незамеченными [Whalen, Whalen, Henderson, 2002: 255].

В силу интереса этнометодологов к способам производства локального порядка, исследователи обращались к перспективе и опыту диспетчеров даже в большей степени, чем авторы ранних критических исследований колл-центров, использовавшие материалы опросов и интервью сотрудников.

Стандартизация и попытки унифицировать работу операторов тоже не остались незамеченными. Одно из важных направлений в ЭМСА рассматривает, как именно институциональный контекст производится участниками разговора [KevoeFeldman, 2019; Heritage, Clayman, 2010; Drew, Heritage, 1992; Whalen, Zimmerman, 1987; Zimmerman, 1992a]. Перспектива "институционального разговора" позволяет замечать асимметрию в выстраивании диалога или привлекать внимание не только к тому, что коммуникативные ресурсы сотрудников колл-центров оказываются ограничены из-за организации работы в колл-центре, но и к тому, как эта ограниченность производится или обходится на практике [Cameron, 2008].

Таким образом, при определенном фокусе две перспективы (критические и ЭМСА исследования) оказываются хорошо совместимы. Детальный анализ диалогов между клиентами и сотрудниками колл-центров позволяет сделать наблюдаемым менеджерское давление на операторов [Cameron, 2008; Hultgren, Cameron, 2010], а также показать, что "рутинные» операции являются результатом искусной работы здесь и сейчас. 


\section{Русскоязычные исследования колл-центров}

Русскоязычных исследований колл-центров достаточно немного. Опубликованные работы преимущественно концентрируются на детальном анализе разговоров с роботом-оператором - голосовым помощником, отвечающим за часть разговоров в том же колл-центре, данные из которого мы анализируем в основной части статьи.

Андрей Корбут показывает, как устроен феномен непонимания в разговоре. Непонимание требует скоординированных действий участников коммуникации, что становится проблематичным в разговорах с роботом, который не обучен способам демонстрации непонимания [Корбут, 2018]. Алиса Максимова рассматривает, как абоненты справочной службы приспосабливаются к другим особенностям переговоров с роботом, экспериментальным образом выясняя его возможности и ограничения. Поскольку голосовой помощник не способен подстроиться под особенности абонентов или озвучить набор своих возможностей, "настройка" предполагает односторонний характер работы со стороны пользователя [Максимова, 2020].

В другом тексте Максимова сравнивает взаимодействие абонентов с роботом и с операторами [Максимова, 2019]. Она показывает, как, в отличие от роботов, операторы работают с внутренними правилами колл-центра и общепринятыми правилами коммуникации, модифицируя их, чтобы добиться собственных целей (например, не допустить, чтобы абонент повесил трубку, не добравшись до конца сценария) и выполнить запрос абонента [там же]. Голосовой помощник такую работу выполнять не способен, и она целиком ложится на звонящего.

Андрей Корбут также обращает внимание на отличия между коммуникацией с роботом и человеком-оператором, показывая, как и в каких ситуациях пользователи справочной службы оказываются недовольны роботом [Корбут, 2019]. Демонстрация недовольства в разговорах с роботом является следствием того, что абоненты понимают и подчеркивают разницу между человеком и машиной, а не того, что они это различие игнорируют.

\section{Методология}

В этом тексте мы придерживаемся эмпирического подхода ЭМСА и фокусируемся на разговорах между операторами колл-центров и звонящими. Корпус данных, из которых были выбраны фрагменты для анализа, включает детальные расшифровки 60 разговоров с операторами колл-центра (глоссарий символов транскрипции представлен в приложении). Имена и другие сведения, позволяющие идентифицировать участников разговора, изменены.

При этом записи звонков интересуют нас не только как материал, позволяющий лучше понять организацию разговора, но материал, отражающий организацию работы колл-центра. Наша задача, тем не менее, заключается в том, чтобы показать, как устроен труд операторов колл-центра не только с точки зрения организации контроля, но и с точки зрения его созидательной стороны.

Дж. Вудкок отмечает, что колл-центры почти никогда не производят ничего общественно полезного, из-за чего работа там настолько эмоционально тяжела, а менеджерский контроль играет такое большое значение [Woodcock, 2017]. Это справедливо не для всех колл-центров. Колл-центр, который мы изучаем, 
работает в качестве справочной службы, которая дает гражданам информацию о государственных услугах и функционировании госструктур. Полностью в ключе описания Урсулы Хувз, операторы этого колл-центра выступают "посредниками" [Huws, 2009] между миром государственных служащих с их специфическим языком и миром простых граждан. Несмотря на свое зависимое положение и статус низкоквалифицированных рабочих, операторы выполняют важную работу переводчиков, в этом смысле они точно также вовлечены в распространение знания, как представители более "престижных" работ (например, журналисты, или университетские преподаватели). Остерегаясь попасть в ловушку менеджерского взгляда на труд, мы посмотрим на навыки, которые позволяют операторам выполнять эту работу. Такой выбор фокуса связан не с отрицанием значимости принуждения в колл-центре, а с намерением продемонстрировать, что финальный продукт создается вопреки контролю и только благодаря мастерству сотрудников.

\section{Организация колл-центра}

Колл-центр, рассматриваемый в этой статье, выполняет функции справочной службы. Формально он является коммерческой организацией, которая действует в интересах одной из государственных структур.

В классификации колл-центров наш колл-центр - это inbound колл-центр: операторы только отвечают на звонки, но не звонят клиентам сами. Колл-центр был специально организован и действует только как государственная информационно-справочная служба. Однако формально операторы не имеют отношения к государству, не позиционируют себя и не позиционируются менеджерами как сотрудники государственных органов.

Исчерпывающий список вопросов, по которым можно звонить в этот коллцентр, для абонентов не определён. Любой желающий может обратиться за консультацией по широкому кругу вопросов, которые так или иначе связаны с работой государственных и муниципальных структурами. Например, он подал документы и желает узнать, готовы ли они; имеет вопрос о том, как и где оказывается та или иная государственная услуга; как функционирует государственная или городская служба или любой другой схожий вопрос.

Формально операторы обладают минимальной свободой влиять на содержание разговоров. Когда звонок поступает в колл-центр, он распределяется между операторами. После того, как оператор приняла звонок, она обязана следовать следующему сценарию разговора:

1. 0 Специалист [Имя], добрый день, как я могу к

2. вам обращаться?

3. 3 добрый день, [имя абонента]

4. 0 [Имя абонента], чем я могу вам помочь?

Из-за наличия сценария первые фразы в разговоре почти всегда звучат одинаково. После этого звонящий озвучивает запрос, оператор должна перевести звонок в режим ожидания (время паузы подсчитывается и контролируется), вбить 
запрос в "базу знаний", найти и зачитать из нее информацию. Как отметила одна из менеджеров колл-центра, зачитывание информации из базы обязательно: отступление от этого правила наказывается штрафами (точнее, снижением оценок работы оператора, которое приводит к лишению премии и уменьшению зарплаты). Опытные операторы имеют тенденцию отходить от текста и опираться на свою экспертизу, что порицается менеджментом под предлогом недостаточной компетенции операторов и намерения спасти их от ошибки:

Оператор сам не имеет права пропустить ни единого слова речовки, если только... если житель сразу его не передвигает на пункт ниже. Это нарушение, если консультация идет не по базе знаний, если оператор не зачитывает полностью, говорит от себя.

Был спорный вопрос, почему ребята должны все-таки зачитывать, но решили, что так как они в органах исполнительной власти не работали, то они могут неправильно интерпретировать тот или иной термин, то или иное предложение, поэтому строгое зачитывание, чтобы не допускалось двоякой и́нтерпретации какой-то. Опять же избавить себя от ошибки. У линии имя серьезное, работаем на серьезного человека, нам таких ошибок допускать совершенно нельзя. (Из интервью с менеджерами колл-центра)

После того, как оператор зачитала информацию, она должна уточнить, остались ли у звонящего дополнительные вопросы, попросить звонящего оставаться на линии для оценки качества ее работы и попрощаться.

С точки зрения попыток унифицировать работу операторов рассматриваемый в этой статье колл-центр является типичным: как показывают другие исследования колл-центров, наличие скриптов или сценариев разговора, которые обязаны соблюдать операторы, является одним из ключевых элементов организации труда [Hultgren, Cameron, 2010; Cameron, 2008; Huws, 2009; Woodcock, 2017].

В реальности, однако, структура разговора оказывается сложнее, чем предполагает стандартный сценарий. Вопрос звонящего не всегда сформулирован как вопрос и далеко не всегда соотносится с рубрикаторами базы знаний. Оператор в таком случае должна помочь звонящему сформулировать запрос и соотнести этот запрос с информацией из базы. Так как звонящий часто остается неудовлетворен формальным ответом, оператору требуется ответить на один или несколько уточняющих вопросов.

Сложность производства ответа заключается не только в том, чтобы найти релевантную информацию в электронной базе или сделать бюрократический язык понятным звонящему, но и в том, чтобы соотнести абстрактную информацию из базы с конкретными запросами. Как показывают Вален и Циммерман, это одна из ключевых задач, которую выполняют и сотрудники диспетчерских служб [Whalen, Zimmerman, 1987; Zimmerman, 1992b].

Формально работа операторов состоит в том, чтобы искать и зачитывать информацию из базы готовых ответов. На деле их задача гораздо сложнее: они должны соотносить общие сведения с конкретными ситуациями, переводить язык бюрократии на общедоступный язык, зачастую оперируя неполной информаци- 
ей и общаясь с раздраженными абонентами. При этом операторы оказываются в сложной ситуации, когда их дискурсивные ресурсы искусственно ограничены внутренними правилами колл-центра. Например, оператор не может ответить "не знаю". Даже в ситуациях, когда она действительно не знает или не может найти ответ, оператор должна создать видимость ответа - произвести реплику, которая будет распознаваема как ответ внутри колл-центра и напоминать ответ для обычного человека. Далее мы увидим, как операторы справляются с этими требованиями на практике, анализируя профессионализм операторов на материалах звонков в справочную службу.

Перед тем как перейти к эмпирической части, мы должны сделать заключительную ремарку о понимании того, что такое профессионализм. Наш ситуативный подход к анализу и критический взгляд на стандартизацию не предполагает, что можно дать формальное определение профессионализма или представить гайдлайн, фиксирующий список пунктов, определяющих профессионального оператора. Опираясь на теорию приобретения навыка, предложенную Хьюбертом Дрейфусом [Dreyfus, Dreyfus, 1980], мы можем лишь сказать, что профессионализм состоит в умении оперировать правилами в конкретных ситуациях. Навык и профессионализм существуют в практиках, то есть содержатся в тех ситуациях ответа на вопрос, которые мы анализируем в эмпирической части. Мы предполагаем, что, чтобы оценить профессионализм операторов, нужно увидеть, в чем заключается сложность производства ответов на вопросы внутри тех организационных рамок, в которых находятся операторы.

\section{Работа в колл-центре: ситуативный подход к анализу профессионализма}

Эмпирическая часть статьи структурирована следующим образом: сначала мы покажем, в чем заключается «перевод" как основной прием, который используют операторы. Далее мы рассмотрим лексический перевод и перевод уникального в типичное в нескольких случаях - когда звонящий сформулировал свой запрос и когда ему требуется помощь в том, чтобы подобрать подходящую для данного институционального контекста формулировку. В третьей части мы сравниваем работу нескольких операторов и голосового помощника, показывая, что успешный «перевод" и производство понятного ответа на вопрос - профессиональное достижение операторов, которое не присутствует в разговоре по умолчанию. Четвертый раздел показывает, как организационная структура колл-центра отражается в тактиках операторов и какие проблемы в коммуникации она может создавать.

\section{1. Перевод как ключевой элемент работы оператора}

Значительная часть работы оператора состоит в том, чтобы переводить или операционализировать понятия из бюрократического языка на язык, который будет понятен звонящему, и наоборот. Перевод нужен, чтобы отправить запрос в базу знаний и выдать ответ, который бы устроил клиента справочной службы. Перевод может выглядеть достаточно просто, как в примере ниже, или включать отдельную последовательность запросов и уточнений. Для начала мы рассмотрим простейший пример перевода, чтобы показать, что мы имеем в виду под этим типом операций. 


\section{Фрагмент 1}

160 Владимир скажите пожалуйста биометрический паспорт

\section{7 (2.3) или (0.2) старого [образца на]}

18 А [такс:::]

190 пять или де[сять лет]?

20 А [нет но-] нового но[вого]

210 [ново]го

22 образ[ца биометри]ческий

23 А [*нового образца* $]$

В первом фрагменте оператор (0) сразу же после уточняющего вопроса о паспорте объясняет абоненту (A) различия между “биометрическим" паспортом и паспортом "старого образца". Первый действует десять лет, второй - пять. Пояснение здесь вызвано реакцией собеседника, который сначала не отвечает на вопрос о том, является ли его паспорт биометрическим (долгая пауза в 2.3 секунды в строке 16), а затем прямо обозначает замешательство ("такс:::"). Замешательство разрешается, когда оператор проговаривает отличия в сроках действия между двумя типами паспорта, после чего звонящий может выбрать подходящую категорию, хотя по-прежнему путается в классификациях. Для абонента существует паспорт старого и нового образца, тогда как в базе данных оператора паспорта бывают биометрическими и старого образца. Оператору требуется сделать еще один перевод и соотнести классификацию звонящего с классификацией базы знаний, что происходит в строке 21-22 ("нового образца - биометрический»).

\section{2. Перевод уникального в типичное и наоборот}

Перевод - это не только перевод формулировок, но перевод конкретного в абстрактное и обратно. Запросы в справочную обычно касаются конкретных деталей частной жизни, которые в определенном смысле уникальны для каждого из клиентов колл-центра, тогда как информация в электронной библиотеке операторов по определению носит общий характер. Работа оператора заключается в том, чтобы соотнести уникальный запрос звонящего с общей информацией из нормативно-правовых актов и инструкций. Как и другую коммуникативную работу, эту работу собеседники выполняют вместе, но принципиальная ответственность за нее ложится на оператора.

\section{Фрагмент 2}

1 К здравствуйте (0.8) >меня Фархид зовут< э хотели бы

2 узнать пожалуйста ээм завтра смогу патент забрать

3 (1.4)

40 вы хотите узнать график работы многофункционального

5 миграционного центра >правильно я понимаю<=?

$6 \mathrm{~K}=$ ну да УФМС и там хотели завтра вот приехать патент

7 нам сообщение пришол вот узнать хотели можем завтра п-

8 поехать забрать

$9(0.7)$ 
10 о оставайтесь пожалуйста на линии я уточню

11 информацию

12 Кугу

13 ((музыка, оператор ищет информацию в базе))

14 О Фархид, спасибо за ожидание (0.6) многофункциональный

15 миграционный центр работает ежедневно с

16 8:00 до 20:00 без перерыва на обед без выходных и без

17 праздничных дней

$18(0.9)$

$19 \mathrm{Ka::} \mathrm{хор} \mathrm{короче} \mathrm{завтра} \mathrm{сможем} \mathrm{да?} \mathrm{поехать} \mathrm{и} \mathrm{забрать}$

20 патент

21 (1.0)

22 д да всё верно

В фрагменте 2 сразу несколько переводов. Сначала конкретный вопрос "Могу ли я забрать патент завтра?» нужно перевести в запрос, ответ на который можно найти в базе знаний: это вопрос о часах работы государственной структуры "многофункциональный миграционный центр". Звонящий знает этот центр как УФМС, так что оператору нужно еще и соотнести название двух бюрократических структур, что она делает без дальнейших уточнений в разговоре со звонящим. Можно представить, что, если бы оператор слепо следовала инструкции, ей пришлось бы устанавливать, что УМФЦ и ММЦ - это одна и та же организация. В данном случае она обходится без дополнительных уточняющих вопросов.

После первого раунда оператор без изменений зачитывает ответ о часах работы ММФЦ. Несмотря на строгое соответствие инструкции, ответ не соотносится с частным вопросом звонящего. Поэтому звонящий задает уточняющий вопрос, по сути повторяя свою первую формулировку: может ли он завтра поехать и забрать патент. Теперь его вопрос носит утвердительную форму с вариантами ответа "да/нет", которую оператор должен подтвердить или опровергнуть. Отвечая утвердительно, оператор заканчивает второй раунд перевода, предоставляя прямой окончательный ответ на вопрос абонента.

Если попытаться формализовать описание, в отрывке выше происходит как минимум два перевода: (1) конкретный запрос "можно ли забрать документ" переводится в вопрос о часах работы организации, который понятен базе знаний; (2) общий ответ о часах работы переводится обратно в ответ, который соотносится с уникальными обстоятельствами звонящего.

Оператор искусно соотносит институциональный (бюрократический) контекст с контекстом обыденной коммуникации. При этом она действует так, чтобы соблюсти правила колл-центра и сохранить целостность коммуникации, прямо ответив на вопрос абонента.

Довольно часто звонящим требуется помощь не только с поиском ответа, но и с формулировкой вопроса. Пример такого случая представлен во фрагменте 3, где оператору сначала нужно помочь сформулировать запрос, затем перевести запрос в форму, пригодную для поиска в базе, а затем сформулировать ответ так, чтобы он соответствовал и вопросу звонящего, и формальным требованиям колл-центра. 


\section{Фрагмент 3}

4 А здравствуйте (0.4) $\uparrow$ а вы мне не подскажете (0.3) вот

5 уэ::: (.) у меня двое новорожденных ^детей

$6(0.4)$

70 та: $\mathrm{k}$

$8(0.6)$

9 А и я их хотел бы прописать э: :

ну у себя в квартире(0.6)

10 я не (.) я не являюсь собственником но прописан

$11(1.8)$

120 я слушаю вас $\underline{\text { Антон }}$

$13(0.8)$

14 А вот (.) и у меня такой вопрос могу ли я это сделать как

15 ну вот прийти в МФЦ и прописать без собственника

$16(1.0)$

170 то есть $x$ >нужно ли согласие собственника при

18 регистрации новорож[денн]ых $<$

19 А [да]

200 детей

21 А да [да да*]

220 [при условии т-] то- того что <вы там

23 зарегистрированы> (.) †да [и вы] отец

$24 \mathrm{~A}$ [да]

250 правильно понимаю Ан[тон]

26 А [да] *да* да совершенно верно

270 Антон оставайтесь пожалуйста на линии я уточню

28 информацию

$[\ldots]$

33 о спасибо за ожидание (.) Антон x::(0.7)

34 но[вор]ождённого

35 А [да да]

360 ребёнка можно прописать >только по месту регистрации

37 одного из родителей по их обоюдному согласию< <при этом

38 согласие собственника> или остальных зарегистрированных

39 на этой жилплощади не нужно

$40(0.6)$

41 А а:: всё я вас (0.3)

420 не нужно (1.3) только

43 А * то есть*

440 согласие родителей

45 А ну то есть только согласие жены

$46(0.7)$

470 да (.) *да* 
Оператор подключается еще на этапе уточнения вопроса, который изначально сформулирован как история. Звонящий, с одной стороны, достаточно компетентен, чтобы выбрать релевантные для этого институционального контекста категории (дети - новорожденные, он не собственник, но прописан; под вопросом необходимость согласия собственника), но недостаточно компетентен, чтобы облечь запрос в вопросительную форму. Кроме того, первая формулировка вопроса прямо не соотносится с той информацией, которая содержится в базе оператора, поэтому оператор помогает абоненту переформулировать вопрос так, чтобы он по-прежнему соотносился с историей звонящего, но давал возможность найти ответ в электронной системе.

Формулировка вопроса, которую подсказывает оператор, является чем-то промежуточным между запросом для базы и запросом, который интересует звонящего. В соответствии с рабочей инструкцией оператора вопрос, сформулированный как вопрос с вариантами ответа "да / нет" ("то есть нужно ли согласие собственника при регистрации новорожденных"), получает гораздо более развернутый ответ из библиотеки (строчки 36-40: «ребенка можно прописать только по месту регистрации одного из родителей..."). При этом, зачитывая речовку, оператор проводит дополнительную работу интонацией, подчеркивая релевантные места и опуская, т. е. прочитывая слишком быстро, то, что к конкретному запросу не относится. Информацию о регистрации родителей оператор прочитывает очень быстро, но на моменте, когда упоминается согласие собственника, замедляется и отдельно выделяет голосом - "не нужно". После паузы оператор дополнительно суммирует только что прочитанный ответ, повторяя "не нужно" (42 строчка) - прямой ответ на вопрос, совместно сформулированный абонентом и оператором в начале разговора. В конце фрагмента стороны дополнительно подтверждают взаимопонимание, устанавливая, что "согласие родителей" в этом конкретном случае означает согласие жены абонента.

Диалог выше - пример техничной работы оператора, которая способна помочь звонящему с формулировкой вопроса, сориентироваться в базе знаний, соблюсти требования колл-центра и дать ответ, который соответствует нормам обыденной коммуникации. "Переводов" в этом относительно небольшом отрывке по меньшей мере три: (1) перевод первоначальной формулировки в вопрос, который можно найти в библиотеке оператора, (2) перевод этого вопроса в форму, пригодную для поиска в базе знаний, и (3) обратный перевод, соотносящий абстрактную информацию из базы с конкретным запросом звонящего. Работа происходит совместно со звонящим, но требует профессионализма оператора, который способен лавировать между наборами не слишком хорошо соотносящихся требований.

\section{3. Профессионализм оператора}

Профессионализм операторов легко оценить, если сопоставить их работу с той работой, которую не делает робот. Коммуникативные способности робота целиком определяются заложенным в него набором алгоритмов - правил, которым он следует без каких-либо отклонений. В смысле стандартизации робота можно считать идеальным сотрудником, который неукоснительно соблюдает любые внутренние нормы колл-центра. Единственная проблема заключается в том, что он при 
этом не способен выстраивать коммуникацию и отвечать на запросы абонентов (как, например, во фрагменте 4, где робот по понятным причинам оказывается совершенно не способен соотнести стандартизированный ответ с конкретным запросом абонента).

\section{Фрагмент 4}

Робот: «данные отправлены для изготовления социальной карты (.) ожидайте получения результата (0.4) вам ґповторить (0.5) ((сигнал)) (1.1)

Звонящий: э- э- т- (0.7) то есть ещё не гото: ва так получается? (1.9) а страховое свидетельство [( )]

Робот: [если у вас] остались вопросы (.) просьба чётко сформулируйте и говорите после звукового сигнала" [Максимова, 2020. С. 125].

Такая некомпетентность робота в одном из ключевых элементов работы в коллцентре дополнительно подтверждает, что работа оператора подразумевает отход от правил. Однако отступление от правил должно быть сделано определенным образом: поскольку несоблюдение некоторых норм чревато санкциями со стороны руководства, а некоторые нормы колл-центра и задачи операторов противоречат общепринятым способам организации разговора, квалификация операторов включает умение справляться с противоречивыми требованиями, избегая санкций руководства и недовольства абонентов.

Ответ, который зачитывает оператор, должен выглядеть как ответ с точки зрения "нормального" разговора, не содержать неверной информации (это чревато штрафами и/или недовольством пользователя), а также не отходить от базы знаний (это грозит штрафами). Соблюдение всех этих требований далеко не всегда значит, что ответ будет типичным с точки зрения обыденного разговора.

Фрагмент ниже - удачный пример выхода из ситуации, где оператор должен ответить на вопрос абонента и соблюсти инструкцию, зачитывая большие объемы текста из базы знания. Несмотря на громоздкость итоговой формулировки, оператор оказывается успешна в соблюдении двух наборов требований: она одновременно отвечает на очень конкретный запрос абонента и следует правилу колл-центра, согласно которому она обязана целиком и без изменений зачитать статью из базы знаний.

\section{Фрагмент 5}

50 Артем чем я [могу вам помочь

6 А [Светлана а подскажите (0.4) подскажите

7 пожалуйста:: смотрите:: : улица пятая парковая=ґдом

8 тридцать восемь $\times(0.8)<$ в интернете написано $\uparrow$ до: $\mathrm{M}($.

9 включен (.) в программу ренова: ция> (х) (0.2) 
10 и я *хотел бы узнать(.)* а когда будет его расселение:? ((часть транскрипта пропущена))

11. 0 >А: ндрей=спасибо за ожидание< (0.2) между включением дома 12. в программу реновации: (.)и его фактическим сносом (.)

13. может пройти несколько лет (0.8)

14. >до первого января [две<]тысячи восемнадцатого года

15. K $[\mathrm{a}::]$

16. 0 будут (.) разработаны (.) необходимые нормативно (.)правовые (.)

17. акты (.) до первого авгу[ста две тысячи] девя:: тнадцатого

18. $\mathrm{K}[\mathrm{a}: \mathrm{:} \mathrm{H}]$

19. О года (.) необходимая (.) градо (.) строительная документация

20. (0.2) х конкретные этапы: э программы ренова: ции и >сроки их

21. реализации< определят не позднее <тридцать первого

22. декабря(0.6)> две тысячи девятнацатого года по мере готовности

23. градостроительной документации (.)[реа реализовать про]грамму

24. К [>ну ладно< я поня:: л]

25. 0 (0.5) х реновации [планируется] в течение пятнадцати лет (.)

26. $K[y x y]$

350 (.) до:: (.) две тысячи тридцать второго года (0.5)

36 сроки сноса (.) для каждого дома (.)предстоит определить

37 индивидуально (0.7) э: м (0.2) всех жильцов обязательно

38 проинформирует управа района (0.5) эм (0.1) подробности

39 программы ренова: ции (0.3) м (0.1) можно узнать

40 в информационных центрах упра: в (0.3) и префектур (0.5)

41 а также вся новая информа: ция публикуется на официальном

42 сайте (.)Мос точка ру (.) в разделе: э (0.5)

43 *московский стандарт реновации*

44 (1.1)

45 A *угу*

$46(0.5)$

470 ДЛЯ ПО[ЛУЧЕНИЯ вСеЙ]

$48 \mathrm{~A} \quad[>$ нет я хотел бы уз]нать< (1.6) просто::: э (.)

49 говорили список будет (0.2) который (.) дома

50 в ближайшее время (обязуются) >я хотел бы узнать<

51 нет ли такого [списка] еще получается [правильно?]

520 [пока э] [пока >такого]

53 списка< *нет* (1.1) *пока не[е: т*]

$54 \mathrm{~A} \quad[*$ я понял (.)]

55 все (.) спасибо* (0.4) угу (0.4) до свидания

Во фрагменте 5 в ответ на достаточно конкретный вопрос абонента оператор в течение двух минут зачитывает информацию из базы знаний. Абонент реагирует минимальными репликами и дважды пытается прервать ответ ("ну ладно, я понял" в строке 24, "нет я хотел бы знать" в строке 48). После того как оператор зачитала статью, абоненту наконец удается перехватить черед и переформули- 
ровать изначальный запрос в конкретный вопрос о том, существует ли список домов для расселения. На этот раз оператор, которая уже зачитала обязательный текст, ограничивается прямым коротким ответом ("списка нет"), который устраивает абонента. В итоге оператор оказывается способна выполнить и требования руководства, без изменения зачитав информацию, и абонента, прямо ответив на вопрос о существовании списка. Приоритет при этом отдан соблюдению внутренних правил колл-центра: пока оператор не зачитала речовку, она не может или ограничена в возможности прямо ответить на вопрос.

\section{4. Ограниченные коммуникативные ресурсы}

Оператор ограничен в части коммуникативных ресурсов и знаний. Она не может отказаться говорить о вопросе, в котором недостаточно компетентна, или потратить слишком много времени на чтение или поиск информации. Эти ограничения могут вызывать странные с точки зрения обыденного взаимодействия ситуации, когда оператор более или менее удачно избегает прямого ответа на вопрос звонящего.

В следующем фрагменте можно видеть относительно неудачный пример избегания, в котором оператор игнорирует требования повседневной коммуникации и обращается к скрипту, чтобы уйти от прямого ответа на вопрос звонящего.

\section{Фрагмент 6}

47 А угу (0.2) то есть если мы электронно подадим заявку

48 *находясь в другом регионе*, да? (0.3) аэ:: (0.4)

49 то:: (.) девочка может приехать со мной (.) только

50 на получение, *правильно я так поняла*?

$51(0.7)$

520 x:: : (0.1) получить информацию по алгоритму

53 оформления на портале вы можете в <центре

54 поддержки пользователей> запишите пожалуйста номер

55 телефона (0.7) х технической под[держки гос

56 A $\quad$ гговорите<

Разговор в этом отрывке касается того, должен ли ребенок звонящей лично присутствовать при подаче заявления на смену регистрации. Ребенок живет в другом городе и должен проделать долгий путь, чтобы подать заявление в местном отделении государственных услуг (а затем проделать его еще раз, когда заявление будет одобрено). В начале разговора, транскрипт которого мы не приводим из-за ограничений места, оператор дает ошибочный ответ, заявляя, что физическое присутствие ребенка обязательно при подаче заявления и при получении ответа. Однако, как выясняется дальше, это требование справедливо только при личной подаче заявления в офисе. Если же заявка подается через портал государственных услуг, присутствие обязательно только при получении. Другими словами, ранее в разговоре оператор допустила ошибку, которую она отказывается признать.

В фрагменте 6 звонящая задает оператору прямой вопрос с вариантами ответа "да" или "нет" ("девочка может приехать только на получение, правильно я по- 
няла?"), в ответ на который оператор зачитывает информацию из базы знаний ("получить информацию по алгоритму оформления..."). Как легко заметить, ответ довольно плохо соотносится с формулировкой вопроса, хотя соответствует внутренним гайдлайнам колл-центра.

В данном случае избегание ответа может быть связано в тем, что оператор отказывается признать свою ошибку и пытается использовать скрипт разговора как "щит", который позволит ей уйти от прямой конфронтации с абонентом (Кэмерон [Cameron, 2008] анализирует эту распространенную стратегию операторов более подробно). Впрочем, учитывая, что клиент оценивает работу оператора после окончания звонка, защита оказывается ненадежной, так как уход от ответа вызывает раздражение абонента. Раздражение и гнев для оператора чреваты не только неприятными эмоциями, но и штрафами или дополнительным контролем менеджеров, которые прослушивают звонки, получившие низкие оценки пользователей.

Так или иначе, структура звонка выше позволяет увидеть, что маневрирование между наборами разных требований не является чем-то по умолчанию присутствующим в разговоре.

При этом в определенных ситуациях профессионализм операторов, который сочетается с их ограниченными ресурсами, в особенности - недостатком информации - потенциально чреват даже большими проблемами, чем неспособность соблюсти противоречивые нормы коммуникации. Пример такого случая представлен в следующем фрагменте, где оператор успешно жонглирует требованиями клиента и колл-центра, предоставляя абоненту информацию, в которой она не уверена.

\section{Фрагмент 7}

1. K эээ у меня такой вопрос ээээ я должен подавать на вид

2. на жительство

3. (0.5)

4. 0 так?

5. (1.1)

6. К аээ документы необходимые уже собираю (2.0)

7. прежде чем собрать я могу приехать дээ получить

8. та:: лон

9. (2.3)

10. 0 х:: <вы> имеете в виду можете ли вы сначала приехать

11. записаться а потом уже подавать документы да?

12. (0.7)

13. 0 Мур[ат]?

14. К [да-да] да да (0.4) да

15. 0 Мурат оставайтесь пожалуйста <на линии> я уточню

16. информацию

17. (0.7)

18. ((часть транскрипта пропущена))

19. (1.2) 
20. x:: >по вопросам получения разрешения на временное

21. проживание (.) выдачи (.) или продления вида на

22. жительство или оформления гражданства Российской

23. федерации необходимо да обращаться в

24. многофункциональный миграционный центр (.) прием

25. документов осуществляется< < только по

26. предварительной записи (.) запись на прием

27. производится в миграционном центре на контрольно-

28. пропускном пункте № 6 ежедневно с 8 до 20 ноль ноль (.)

29. при наличии паспорта(.)без предварительной записи

30. могут быть обслужены инвалиды первой группы и

31. престарелые граждане в возрасте свыше $<75$ лет>

32. (1.0)

33. $\mathrm{K}$ угу $=$

44. 0 =то есть вы только сначала записываетесь при наличии

45. паспорта (.) а потом уже (0.6) привозите

46. документы

47. (0.6)

48. А а всё понял >это вот именно мне надо ехать

49. к Никольскому и там получить этот талон да? правильно

50. я понимаю?<=

51. $0=<д а$ с паспортом получить [талон $>$ ]

52. А [именно] возле Никольского

53. (0.6) [я больше нигде не могу?]

54.0 [именно в] миграционном центре больше ниг[де

55. А [ага

56. (0.8)

57. 0 =только В [миграционном центре]

58. A [понял]

59. 0 на [контрольно-пропускном пункте номер шесть]

60. A [спасибо вам огромное]

Прежде всего оператор снова помогает звонящему сформулировать вопрос ("можно ли сначала записаться, а потом приехать подавать документы»). Затем она находит информацию в базе знаний - насколько можно судить по содержанию ответа в строках 20-32, она зачитывает статью “О продлении вида на жительство или оформления гражданства РФ". В уже знакомой манере оператор подчеркивает интонацией и небольшими вставками релевантные места из текста. Она добавляет частицу "да" перед упоминанием "многофункционального миграционного центра", медленнее произносит "только по предварительной записи" (ключевую часть для ответа на вопрос звонящего), выделяет паузами информацию о необходимости наличия паспорта. Кроме того, зачитав речовку, она делает паузу и дополнительно обобщает информацию из статьи, делая ее полностью релевантной для вопроса абонента ("то есть вы только сначала записываетесь при наличии паспорта, а потом уже привозите документы"). Судя по реакции звонящего, ко- 
торый на первое долгое зачитывание информации реагирует только коротким "угу" после достаточно долгой паузы в стоке 32, а на резюме отзывается гораздо более эмоциональным "а все понял", обобщение оператора делает ответ более понятным для абонента.

Потенциально проблематичная ситуация возникает, когда звонящий пытается уточнить адрес, по которому он должен получить талон для записи (начиная со строк 48-49). Хотя первый уточняющий вопрос абонента касается места (“надо ехать к Никольскому?»), оператор отвечает утвердительно на другой вопрос ("да, с паспортом»). Звонящий пытается повторить вопрос про место ("именно возле Никольского?»), но опять получает уклончивое "именно в миграционном центре, больше нигде". Хотя оператор до конца содержательно не отвечает на вопрос абонента, форма ответа выглядит как утвердительный ответ.

Мы предполагаем, что оператор прибегает к такой формулировке из-за того, что она одновременно ограничена в коммуникативных ресурсах и возможностях поиска информации. Хотя в статье, которую зачитывает оператор, нет информации о местонахождении миграционного центра, она не располагает возможностью отказаться от ответа или не предоставить сведения абоненту. Поэтому она прибегает к нескольким уловкам, давая прямой утвердительный ответ, но не на тот вопрос, который интересует абонента. Вопрос об адресе с вариантами ответа "да" и "нет" получает два утвердительных ответа ("да с паспортом", "да в ММФЦ"), которые не релевантны запросу абонента, но содержатся в базе знаний. Хотя в данной ситуации оператор не дает неверной информации, можно представить, что такая коммуникативная компетентность при ограниченных знаниях может привести к передаче неверных сведений. При этом данную стратегию оператора также можно рассматривать как стратегию самозащиты (от требований колл-центра и от запроса звонящего, оставление которого без ответа чревато раздражением и/или низкими оценками), которая оказывается намного успешнее, чем стратегия из предыдущего примера.

Фрагмент 7 в очередной раз демонстрирует, что компетенция операторов подразумевает умение лавировать между противоречивыми требованиями в условиях неопределенности, ограниченных коммуникативных ресурсов и знаний, а также постоянной угрозы попасть под санкции со стороны абонента или руководства колл-центра. Однако такое давление на операторов не только усложняет их работу, но и снижает качество услуг.

\section{Заключение}

Наш текст сфокусирован на каждодневной работе операторов и тех навыках, которые позволяют операторам компетентно отвечать на вопросы клиентов справочной службы. Разговор о навыках и рабочих практиках важен, так как позволяет увидеть, что работа в колл-центре требует профессионализма операторов, без которого справочная служба не могла бы существовать.

Мы надеемся, что это исследование сделает вклад в российские исследования труда [Хумарян, Жихаревич, Коновалов, 2020; Гудова, 2020] эмпирически и методологически, демонстрируя, как этнометодологический фокус на содержании труда позволяет избежать перспективы, в которой труд оказывается важен только с точки зрения менеджерских практик управления и контроля над персоналом. 
Мы предполагаем, что разговор про навыки и рабочие практики, важен, так как позволяет увидеть, что работа в колл-центре требует профессионализма операторов, без которого справочная служба не могла бы работать.

Сотрудники рассматриваемого колл-центра выполняют важную общественную функцию, распространяя информацию о функционировании государственных структур в понятном для обычных людей виде. Поскольку клиенты справочной службы в большинстве случаев не являются экспертами по тем вопросам, по которым им нужна консультация, Алиса Максимова (2019) сравнивает работу операторов с работой терапевта, который диагностирует болезнь на основе невнятных жалоб пациента. Это работа также напоминает работу переводчика или проводника между двумя институциональными мирами (см. об этом: [Huws, 2009]) - миром бюрократических структур и нормативных документов установленного образца и повседневным миром уникальных жизненных ситуаций.

Как мы постарались показать выше, ключевая и самая сложная часть работы операторов заключается не в том, чтобы найти релевантную информацию в электронной базе данных и зачитать ее абоненту, и даже не в том, чтобы сделать бюрократический язык понятным для неспециалиста, но в том, чтобы соотнести абстрактную информацию из базы с конкретными запросами. Запрос (если он сформулирован как вопрос) зачастую касается обстоятельств частной жизни, которые в определенном смысле уникальны, тогда как информация, доступная операторам, носит общий характер. Работа операторов состоит в том, чтобы сделать абстрактные сведения применимыми к конкретным ситуациям.

Операторы постоянно маневрируют между индивидуальными и институциональными целями: они заинтересованы в том, чтобы дойти до конца сценария разговора, зачитать информацию без изменений, предоставить верную информацию и исчерпывающе ответить на вопрос клиента, но также соблюсти нормы повседневной коммуникации, чтобы не вызвать раздражение собеседника. Это набор часто противоречивых задач, которым операторы следуют в ситуации серьезных ограничений, стресса и постоянного контроля руководства.

Необходимость маневрировать между разными наборами требований вынуждает операторов творчески подходить к рабочим инструкциям: работать как со сценарием разговора, модифицируя его с помощью интонации, так и с практиками повседневной коммуникации [Максимова, 2019]. "Робот» - голосовой помощник, принимающий часть звонков в колл-центр, этого делать не способен, что делает его ограниченно применимым для работы в колл-центре.

Операторы должны соблюдать правила колл-центра и правила повседневной коммуникации, которые зачастую противоречат друг другу. Компетенция операторов позволяет им маневрировать между разнородными наборами требований так, чтобы их нельзя было уличить в нарушении любого из них. Как показывает Дж. Вудкок, менеджеры колл-центров больше всего ценят сотрудников, которые способны подойти к исполнению внутренних правил колл-центров таким образом, чтобы максимизировать "качество" разговора [Woodcock, 2017]. В том, что руководство колл-центров больше всего ценит таких "творческих" сотрудников, есть некоторая доля иронии: с одной стороны, колл-центр держится на скриптах, унифицированных стандартах и строгом контроле за их соблюдением, с другой стороны, лучшие с точки 
зрения выстраивания коммуникации сотрудники способны отклоняться от правил, не будучи пойманным за руку (здесь воплощается дилемма "количество - качество", типичная для организации труда в колл-центрах [Bain et al., 2002]).

К похожим выводам приходят исследователи, изучающие работу интервьюеров, работающих на телефонных опросах, которые фактически тоже являются сотрудниками колл-центров. Несмотря на строгие требования унификации опросного аппарата, поддерживать нормальную коммуникацию способны только операторы, ситуативно отклоняющиеся от буквального следования инструкциям, то есть нарушающие принцип стандартизации и оказывающиеся под угрозой быть наказанными за отступление от рабочих правил. В результате "лучшими" с точки зрения выстраивания коммуникации оказываются те, кто нарушает внутренние требования организации [Августис, Широков, 2019; Ипатова, Рогозин, 2014, 2019; Вырская, 2017].

Парадокс заключается в том, что колл-центр способен успешно функционировать только потому, что операторы знают, как и когда отступить от рабочих инструкций, чтобы дать состояться обыденной коммуникации. Профессионализм сотрудников требует прикладных знаний о том, как, когда и какие формальные правила нужно игнорировать, чтобы соблюсти нормы обыденной коммуникации. Поскольку возможность отступления от правил не предполагается внутренними инструкциями, профессионализм операторов существует в условиях риска. Это не значит, что операторы обязательно будут наказаны за любое отступление от правил, однако в спорной ситуации или в случае конфликта только менеджер может решить, было ли отступление от правил оправданным. Таким образом, формальные правила колл-центра не упрощают коммуникацию, а делают ее более рискованной для операторов.

Как было отмечено во введении статьи, маневрирование между формальными правилами не специфично для работы операторов. Колл-центр в этом смысле не является уникальным, как не является он и пространством, существующим вне социальных порядков. Тем не менее, существует разница между бюрократическими правилами и социальным порядком организации, который нельзя исчерпывающе описать через набор инструкций из-за его подвижности и гибкости. Организация труда, при которой зазор между правилами и практикой операторов формально не может быть ничем, кроме нарушения, диспропорционально распределяет контроль между операторами и менеджерами. Таким образом, суть "низкоквалифицированной" работы в колл-центре состоит не в простоте или отсутствии требований к навыкам операторов, а в том, что делать работу операторов качественно можно только под потенциальной угрозой наказания. Организация труда, основанная на тотальном контроле и стандартизации, не дает возможности институционализировать профессиональные компетенции операторов, связанные с ключевой частью их работы - производством ответов на вопросы.

\section{Список литературы (References)}

Августис Ю.И., Широков А.А. Ситуации и методы переспрашивания в телефонных опросах: этнометодологический анализ стандартизированного интервью // Мониторинг общественного мнения: Экономические и социальные перемены. 2019. No 4. С. 22-42. https://doi.org/10.14515/monitoring.2019.4.02. 
Avgustis Yu. I., Shirokov A. A. (2019) Situations and Methods of Re-Asking in Telephone Surveys: An Ethnomethodological Analysis of a Standardized Interview. Monitoring of Public Opinion: Economic and Social Changes. No. 4. P. 22-42. https:// doi.org/10.14515/monitoring.2019.4.02. (In Russ.)

Вырская М. Коммуникационные сбои стандартизованном телефонном интервью //Телескоп. 2017. № 6. С. 12-17.

Vyrskaya M. (2017) Communication Failures in Standardized Telephone Interviews. Telescope. No. 6. P. 12-17. (In Russ.)

Гудова Е. «Письмо должно быть долгожданным»: как устроена темпоральная синхронизация сотрудников в российской почте // Социология власти. 2020. Т. 32. № 1. C. 155-178. https://www.doi.org/10.22394/2074-0492-2020-1-155-178. Gudova E. (2020) "A Letter Should Be Long-Awaited”: the Temporal Synchronization of Russian Post Office Employee. Sociology of Power. Vol. 32. No. 1. P. 155-178. https://www.doi.org/10.22394/2074-0492-2020-1-155-178. (In Russ.)

Ипатова А. А., Рогозин Д. М. Условия коммуникативного успеха в стандартизированном телефонном интервью // Социологический журнал. 2014. № 1. С. $21-54$. Ipatova A. A., Rogozin D. M. (2014) Conditions for Communicative Success in a Standardized Telephone Interview. Sociological Journal. No. 1. P. 21-54. (In Russ.)

Ипатова А. А., Рогозин Д. М. Способы преодоления коммуникативных затруднений в стандартизированном телефонном интервью // Вестник РуДН. Серия: Социология. 2019. № 1. . . 144-166. https://doi.org/10.22363/2313-2272-2019-19-1-144-166. Ipatova A. A., Rogozin D. M. (2019) Techniques for Communication Repair in the Standardized Telephone Interview. RUDN Journal of Sociology. No. 1. P. 144-166. https://doi.org/10.22363/2313-2272-2019-19-1-144-166. (In Russ.)

Корбут А. М. «Простите, я никак не могу понять": способы реагирования на непонимание во взаимодействии человека и робота // Laboratorium. 2018. T. 10. № 3. C. 57-78. https://doi.org/10.25285/2078-1938-2018-10-3-57-78.

Korbut A. M. (2018) "Sorry, I Cannot Understand": Ways of Dealing with NonUnderstanding in Human-Robot Interaction. Laboratorium. Vol. 10. No. 3. P. 57-78. https://doi.org/10.25285/2078-1938-2018-10-3-57-78. (In Russ.)

Корбут А. М. Реакция пользователей на сбои во взаимодействии с компьютерами: социологический анализ / Журнал социологии и социальной антропологии. 2019. № 6. C. 27-43. https://doi.org/10.31119/jssa.2019.22.6.3.

Korbut A. M. (2019) User Reaction to Breakdowns in Human-Computer Interaction: A Sociological Analysis. Journal of Sociology and Social Anthropology. No. 6. P. 27-43. https://doi.org/10.31119/jssa.2019.22.6.3. (In Russ.)

Максимова А. Опыт пользователя телефонной справочной службы: взаимодействие с оператором-человеком и роботом // Журнал социологии и социальной антропологии. 2019. № 6. с. 44-68. https://doi.org/10.31119/jssa.2019.22.6.4. Maksimova A. Telephone Helpdesk User Experience: Interaction with Human Operator and Robot. Journal of Sociology and Social Anthropology. No. 6. P. 44-68. https:// doi.org/10.31119/jssa.2019.22.6.4. (In Russ.) 
Максимова А. Настройка собеседника: Интеракционные барьеры в телефонном разговоре с роботом // Земнухова Л. и др. Приключения технологий: барьеры цифровизации в России. М., СПб.: ФНИСЦ РАН, 2020. С. 95-132. https:// doi.org/10.31119/978-5-89697-339-3.

Maksimova A. (2020) Configuring the Interlocutor: Interaction Barriers in a Telephone Conversation with a Robot. In: Zemnukhova L. et al. Technology Adventures: Barriers to Digitalization in Russia. Moscow, St. Petersburg: Federal Center of Theoretical and Applied Sociology of RASP. 95-132. https://doi.org/10.31119/978-5-89697-339-3. (In Russ.)

Хумарян Д. Г., Жихаревич Д. М., Коновалов И. А. К новым исследованиям труда: вместо предисловия // Социология власти. 2020. Т. 32. № 1. С. 8-29. https:// www.doi.org/10.22394/2074-0492-2020-1-8-29.

Khumaryan D. G., Zhikharevich D. M., Konovalov I. A. (2020) Towards New Studies of Labor: Instead of an Introduction. Sociology of Power. Vol. 32. No. 1. P. 8-29. https:// www.doi.org/10.22394/2074-0492-2020-1-8-29. (In Russ.)

Bain P., Taylor Ph. (2000) Entrapped by the "Electronic Panopticon»? Worker Resistance in the Call Centre. New Technology, Work and Employment. Vol. 15. No. 1. P. 2-18. https://doi.org/10.1111/1468-005x.00061.

Bain P., Watson A., Mulvey G., Taylor Ph., Gall G. (2002) Taylorism, Targets and the Pursuit of Quantity and Quality by Call Centre Management. New Technology, Work and Employment. Vol. 17. No. 3. P. 170-185. https://doi.org/10.1111/1468-005X.00103.

Beynon H. (1975) Working for Ford. London: Allen Lane.

Bolton S. (2004) Conceptual Confusions: Emotion Work as Skilled Work. In: Warhurst C., Grugulis I., Keep E. (eds.) The Skills That Matter. Houndsmill: Palgrave Macmillan. P.19_37.

Braverman H. (1974) Labor and Monopoly Capital: The Degradation of Work in the Twentieth Century. New York, NY: Monthly Review Press.

Callaghan G., Thompson P. (2001) Edwards Revisited: Technical Control and Call Centres. Economic and Industrial Democracy. Vol. 22. No. 1. P. 13-37. https:// doi.org/10.1177/0143831x01221002.

Callaghan G., Thompson P. (2002) "We Recruit Attitude»: The Selection and Shaping of Routine Call Centre Labour. Journal of Management Studies. Vol. 39. No. 2. P. 233254. https://doi.org/10.1111/1467-6486.00290.

Cameron D. (2008) Talk From the Top Down. Language \& Communication. Vol. 28. No. 2. P. 143-155. https://doi.org/10.1016/j.langcom.2007.09.001.

Drew P., Heritage J. (1992) Talk at Work: Interaction in Institutional Setting. Cambridge: Cambridge University Press.

Dreyfus H. L., Dreyfus S. E. (1980) A Five-Stage Model of the Mental Activities Involved in Directed Skill Acquisition. Berkeley: University of California, Operations Research Center. 
Edwards R. (1979) The Transformation of the Workplace in the Twentieth Century. New York, NY: Basic Books.

Fernie S., Metcalf D. (1998) (Not)Hanging on the Telephone: Payment Systems in the New Sweatshops. London: Centre for Economic Performance, London School of Economics and Political Science.

Friedman A. (1977) Industry and Labour: Class Struggle at Work and Monopoly Capitalism. London: Macmillan.

Glucksmann M.A. (2004) Call Configurations: Varieties of Call Centre and Divisions of Labour. Work, Employment and Society. Vol. 18. No. 4. P. 795-811. https:// doi.org/10.1177/0950017004047965.

Heritage J., Clayman S. (2010) Talk in Action: Interactions, Identities and Institutions. Oxford: Wiley-Blackwell.

Hochschild A. R. (1983) The Managed Heart: Commercialization of Human Feeling. Berkeley, CA: University of California Press.

Hultgren C., Cameron D. (2010) How May I Help You? Questions, Control, and Customer Care in Telephone Call Center Talk. In: Freed A., Ehrlich S. (eds.) “Why Do You Ask?”: The Function of Questions in Institutional Settings. New York, NY: Oxford University Press. P. 322-342. https://doi.org/10.1093/acprof: oso/9780195306897.003.0001.

Huws U. (2009) Working at the Interface: Call-Centre Labour in a Global Economy. Work Organisation, Labour \& Globalisation. Vol. 3. No. 1. P.1-8. https://doi.org/10.13169/ workorgalaboglob.3.1.0001.

Kevoe-Feldman H. (2019) Inside the Emergency Service Call-Center: Reviewing Thirty Years of Language and Social Interaction Research. Research on Language and Social Interaction. Vol. 52. No. 3. P. 227-240. https://doi.org/10.1080/08351813.2019 1631038.

Luff P., Hindmarsh J., Heath C. (2000) Workplace Studies: Recovering Work Practice and Informing System Design. Cambridge: Cambridge University Press. https://doi.org/ 10.1017/cbo9780511628122.

Mondada L. (2008) Using Video for a Sequential and Multimodal Analysis of Social Interaction: Videotaping Institutional Telephone Calls. Forum: Qualitative Social Research. Vol. 9. No. 3: Visual Methods. https://doi.org/10.17169/fqs-9.3.1161.

Pupo N., Noack A. (2009) Standardising Public Service: The Experiences of Call-Centre Workers in the Canadian Federal Government. Work Organisation, Labour \& Globalisation. Vol. 3. No. 1. P. 100-113. https://doi.org/10.13169/ workorgalaboglob.3.1.0100.

Taylor Ph., Bain P. (1999) "An Assembly Line in the Head»: Work and Employee Relations in the Call Centre. Industrial Relations Journal. Vol. 30. No. 2. P. 101-117. https:// doi.org/10.1111/1468-2338.00113. 
Taylor Ph., Bain P. (2003) "Subterranean Worksick Blues": Humour as Subversion in Two Call Centres. Organization Studies. Vol. 24. No. 9. P. 1487-1509. https:// doi.org/10.1177/0170840603249008.

Whalen J. (1995) A Technology of Order Production: Computer-Aided Dispatch in Public Safety Communication. In: Have P., Psathas G. (eds.) Situated Order: Studies in the Social Organization of Talk and Embodied Activities. Lanham, MD: University Press of America. P. 187-230.

Whalen J., Whalen M., Henderson K. (2002) Improvisational Choreography in Teleservice Work. British Journal of Sociology. Vol. 53. No. 2. P. 239-258. https:// doi.org/10.1080/00071310220133322.

Whalen M.R., Zimmerman D.H. (1987) Sequential and Institutional Contexts in Calls for Help. Social Psychology Quarterly. Vol. 50. No. 2. P. 172-185. https:// doi.org/10.2307/2786750.

Whalen M. R., Zimmerman D. H. (1990) Describing Trouble: Practical Epistemology in Citizen Calls to the Police. Language in Society. Vol. 19. No. 4. P. 465-492. https:// doi.org/10.1017/s0047404500014779.

Whalen J., Zimmerman, D. H., Whalen M. R. (1988) When Words Fail: A Single Case Analysis. Social Problems. Vol. 35. No. 4. P. 335-362. https://doi.org/ 10.2307/800591.

Wickham J., Collins G. (2004) The Call Centre: A Nursery for New Forms of Work Organisation? The Service Industries Journal. Vol. 24. No. 1. P. 1-18. https://doi.org/ 10.1080/02642060412331301102.

Woodcock J. (2017) Working the Phones: Control and Resistance in Call Centres. London: Pluto Press.

Zimmerman D. H. (1992a) Achieving Context: Openings in Emergency Calls. In: Watson G., Seiler R. M. (eds.) Text in Context: Contributions to Ethnomethodology. Newbury Park, CA: SAGE. P. 35-51.

Zimmerman D. H. (1992b) The Interactional Organization of Calls for Emergency Assistance. In: Drew P., Heritage J. (eds.) Talk at Work: Interaction in Institutional Settings. Cambridge: Cambridge University Press. P. 418-469. 


\section{Приложение}

\section{Глоссарий символов транскрибирования}

[

]

$=$

$=$

(.)

слово

:::

$\uparrow \downarrow$

.,?

СЛОВО

*слово*

(a)

$\mathrm{X}$

$\phi$

XXX

$-$

$><$

$<>$

()

(слово)

((кашляет)
Момент одновременного начала накладывающихся чередов или фрагментов

Момент одновременного окончания накладывающихся чередов или фрагментов либо момент окончания одного из накладывающихся чередов или фрагментов при продолжении другого Отсутствие паузы там, где она может ожидаться (например, в конце предложения)

Отсутствие паузы между чередами разных говорящих (знак «=» ставится в конце одного череда и в начале следующего)

Пауза в целых и десятых долях секунды

Небольшая пауза ( \pm одна десятая секунды) внутри или между чередами

Интонационное выделение посредством смены высоты и/или диапазона голоса

"Растягивание" звука (длина ряда двоеточий соответствует длительности растягивания)

Заметное повышение или понижение высоты голоса в последующем фрагменте (количество стрелок обозначает силу повышения или понижения)

"Обычная" интонация, не грамматика

Фрагмент, произнесенный громче окружающих его фрагментов

Фрагмент, произнесенный тише окружающих его фрагментов

Зарождающийся, но не артикулированный до конца звук

Вдох

Выдох

Смех (количество "Х” соответствует количеству выдохов)

Обрыв череда или слова

Фрагмент, произнесенный быстрее окружающих его фрагментов

Фрагмент, произнесенный медленнее окружающих его фрагментов

Фрагмент, который не удалось разобрать (расстояние между скобками должно соответствовать длине высказывания)

Неуверенность в точности транскрибирования

Комментарии 